\title{
VARIATIONAL INEQUALITIES AND OPTIMAL EQUILIBRIUM DISTRIBUTIONS IN TRANSPORTATION NETWORKS
}

\author{
LAURA SCRIMALI
}

Abstract. We deal with equilibrium problems in transportation networks within a variational framework. In particular, we present some paradoxical results which show how some changes in input data can be successfully exploited by the traffic manager in order to optimize the traffic distribution thus minimizing the total cost. paradox

Mathematics subject classification (2000): 49J40, 90B06, 90C99, 65K10.

Key words and phrases: Variational and quasi-variational inequalities, traffic assingment, Fisk's

\section{REFERENCES}

[1] P. Daniele And A. MaUgeri AND W. OetTLI, Time-dependent Traffic Equilibria, Journal of Optimization Theory and Applications, Vol. 103, No. 3 (1999) 543-554.

[2] M. DE LuCA, Existence of Solutions for a Time-dependent Quasi-variational Inequality, Supplemento Rendiconti del Circolo Matematico di Palermo, Serie 2, Vol. 48 (1997) 101-106.

[3] M. De LuCA AND A. MAUGERI, Quasi-Variational Inequalities and Applications to the Traffic Equilibrium Problem; Discussion of a Paradox, Journal of Computational and Applied Mathematics, Vol. 28 (1989) 163-171.

[4] M. De LuCA AND A. MAUGERI, Variational Inequalities Applied to the Study of Paradoxes in Equilibrium Problems, Optimization, Vol. 25 (1992) 249-259.

[5] F. Giannessi And A. MaUgeri EdS., Variational Inequalities and Network Equilibrium Problems, Plenum Press New York (1995).

[6] F. Giannessi and A. Maugeri AND P. Pardalos EdS., Equilibrium Problems: Nonsmooth optimization and Variational Inequality Models, Kluwer Academic Publishers (2001).

[7] C. FISK, More Paradoxes in the Equilibrium Assignment Problem, Transportation Research Part B, Vol. 13 (1979) 305-309.

[8] A. MAUgeri, Convex Programming, Variational Inequalities and Applications to the Traffic Equilibrium Problems, Applied Mathematics and Optimization, Vol. 16 (1987) 169-185.

[9] A. MAugerI, Optimization Problems with Side Constraints and Generalized Equilibrium Principles, Le Matematiche, Vol. 49 (1994) 305-312.

[10] A. Maugeri AND W. OetTli AND D. SChläGER, A Flexible Form of Wardrop's Principle for Traffic Equilibria with Side Constraints, Supplemento Rendiconti del Circolo Matematico di Palermo, Serie 2, Vol. 48 (1997) 185-193.

[11] L. SCRIMALI, Transportation Networks with Capacity Constraints, in: Equilibrium Problems and Variational Models, eds. P. Daniele, F. Giannessi, A. Maugeri, Kluwer Academic Publishers (2003) 433-445.

[12] M. J. SMITH, The Existence, Uniqueness and Stability of Traffic Equilibrium, Transportation Research, Vol. 138 (1979) 295-304.

[13] J. G. WARDROP, Some Theoretical Aspects of Road Traffic Research, in: Proceedings of the Institute of Civil Engineers, Part II (1952) 325-378. 